2 GSA DATA REPOSITORY 2012158

Pacton et al.

3 METHODS

$4 \quad$ Imaging and elemental analysis

5 Ooidal grains were sampled from a freshly split core and stored at $5^{\circ} \mathrm{C}$ prior to analysis. In order

6 to study their outer cortices, ooid grains were hand-picked under a macroscope (Leica MZ 16

7 APO, University of Zürich) and examined using a JEOL JSM-6400 scanning electron

8 microscope (SEM) after gold-palladium coating. Targeted samples were subsequently embedded

9 in resin, thin sectioned and recoated before further SEM examination in preparation for

10 NanoSIMS analysis.

12 Nano-scale ion mapping was performed using a Cameca NanoSIMS 50 ion microprobe at the

13 University of Western Australia on targeted zones of ooids previously characterized by SEM. A

$14 \mathrm{Cs}+$ primary beam was focused to a beam diameter of c.50 nm, with a beam current of c.3-4 pA.

15 The instrument was operated in multi-collector mode, allowing ${ }^{16} \mathrm{O}^{-},{ }^{24} \mathrm{C}_{2}^{-},{ }^{12} \mathrm{C}^{14} \mathrm{~N}^{-},{ }^{28} \mathrm{Si}^{-}$and ${ }^{32} \mathrm{~S}$

16 together with secondary electrons to be collected simultaneously from the same scanned area,

17 with a dwell-time of $10 \mathrm{~ms} /$ pixel. The sample surface was presputtered with an elevated primary

18 beam current to $>5 \times 10^{16}$ ions $/ \mathrm{cm}^{2}$ (cf. Gnaser, 2003) in order to reach a steady-state of ion

19 emission and to remove surface contamination. Charge compensation was achieved by use of the

20 electron gun. Image sizes were 256 × 256 pixels and fields of view varied from 50 x $50 \mu \mathrm{m}$ (i.e.

21 each pixel was $195 \mathrm{~nm}$ ) to $8 \times 8 \mu \mathrm{m}$ (i.e. each pixel was theoretically $31 \mathrm{~nm}$ but resolution was

22 limited by the beam diameter of c.50 nm). The data were corrected for a detector dead-time of 44

23 ns on the individual pixels. 


\section{Isotopic analysis}

26 Ooids were cleaned with $\mathrm{H}_{2} \mathrm{O}_{2}$ according to the method described in Mikutta et al. (2005).

27 Approximately $150 \mu \mathrm{g}$ of ooids were weighed in the glass vials of a Thermo Fisher ScientificR

28 Kiel IV carbonate device for bulk oxygen and carbon isotopic analyses. The samples were

29 treated with phosphoric acid in a Kiel IV preparation system and analysed in an attached

30 Thermo-electron Delta V Plus mass spectrometer at the ETH Zürich. The values are reported in

31 the conventional delta notation $\left(\delta^{13} \mathrm{C}_{\text {sample }}=\left\{\left[\left({ }^{13} \mathrm{C} /{ }^{12} \mathrm{C}\right)_{\text {sample }} /\left({ }^{13} \mathrm{C} /{ }^{12} \mathrm{C}\right)_{\text {reference }}\right]-1\right\} * 1000\right.$;

$\left.32 \delta^{18} \mathrm{O}_{\text {sample }}=\left\{\left[\left({ }^{18} \mathrm{O} /{ }^{16} \mathrm{O}\right)_{\text {sample }}\left({ }^{18} \mathrm{O} /{ }^{16} \mathrm{O}\right)_{\text {reference }}\right]-1\right\} * 1000\right)$ with respect to the Vienna Pee Dee

33 Belemnite (V-PDB) standard. Reproducibility of the laboratory standard was better than $0.1 \%$

34 for both carbon and oxygen.

36 In situ, spatially resolved oxygen and carbon isotope compositions were determined using a

37 Cameca 1270 ion microprobe at CRPG-CNRS, Nancy, France, following the methodology

38 outlined in Rollion-Bard et al. (2007). Briefly, a primary $\mathrm{Cs}^{+}$beam of $10 \mathrm{nA}$ was focused to a

39 spot size of c. $20 \mu \mathrm{m}$. The normal incidence electron gun was used to compensate for sample

40 charging during analysis. Measurements of oxygen and carbon isotopes were both conducted in

41 multicollection mode, using two off-axis Faraday cups, and one off-axis Faraday cup and the

42 central electron multiplier, respectively. A liquid nitrogen cold-trap was used to lower the gas

43 pressure in the specimen chamber and then to ensure stability of the measurements. The

44 instrumental mass fractionations (IMF) were determined on reference materials of calcite and

45 dolomite to take into account the effect of Mg content on the IMF as described in Rollion-Bard

46 and Marin-Carbonne (2011). The typical acquisition times were $3 \mathrm{~s}$ during 30 cycles for oxygen 
47 analyses and 40 cycles for carbon analyses. Prior to each analysis, the following automated

48 procedure was performed: 1) secondary ion beam centering within the field aperture by adjusting

49 the transfer lens deflector voltages; and 2) magnetic field scanning and peak centering. This

50 procedure leads to internal precision $(1 \sigma)$ better than $0.1 \%$ for $\delta^{18} \mathrm{O}$ and better than $0.2 \%$ for

$51 \quad \delta^{13} \mathrm{C}$, and external reproducibility $(1 \sigma)$ between 0.2 and 0.4 for $\delta^{18} \mathrm{O}$ and c. $0.5 \%$ for $\delta^{13} \mathrm{C}$, based

52 on repeated analyses of reference materials. At the beginning of each analysis in the cortices, the

$53{ }^{13} \mathrm{C} /{ }^{12} \mathrm{C}$ ratio and the count rates were steady, but at depths of $1-4 \mu \mathrm{m}$ the count rates drastically

54 increased suggesting a large contribution from organic material (that gives significantly higher

$55{ }^{12} \mathrm{C}^{-}$and ${ }^{13} \mathrm{C}^{-}$ion yields than carbonate) at this depth. The organic matter contamination was

56 checked by the secondary count rates in oxygen and in carbon. When these count rates were

57 similar to the ones determined on in-house reference materials, it was considered that only

58 carbonate was measured.

60 FIGURE CAPTIONS

61 DR1: SEM images of a single ooid showing A) porous cortex containing B) microbial filaments 62 (red arrows) and EPS (white arrows).

64 DR2: SEM images from a single ooid showing the cortex composed of EPS (dashed arrow in B) 65 and crystals (solid arrow in B). Elemental analysis using EDAX reveals the presence of both 66 low-Mg calcite and Mg-Si permineralized EPS.

68 DR3: A) Elemental analyses (using EDAX) on an ooid grain (same area as Fig. 2b) showing a $69 \mathrm{Mg}$-Silicate enriched cortex in comparison to the quartz nucleus or well-crystallized Low-Mg 
70 calcite. B and C display a high-magnification view of the low right area in A showing both the

71 elemental distribution in selected points and in the mapping of the cortex with respect to the

72 nucleus, respectively.

73

74 REFERENCES

75 Gnaser, H., 2003, Ionization probability of sputtered cluster anions: $\mathrm{C}_{\mathrm{n}}{ }^{-}$and $\mathrm{Si}_{\mathrm{n}}{ }^{-}$: Applied Surface 76 Science, v. 203-204, p. 78-81.

77 Mikutta, R., Kleber, M., Kaiser, K., and Jahn, R., 2005, Review: Organic matter removal from 78 soils using hydrogen peroxide, sodium hypochlorite, and disodium peroxodisulfate: Soil Sci.

79 Soc. Am. J., v. 69, p. 120-135.

80 Rollion-Bard, C., and Marin-Carbonne, J., 2011, Determination of SIMS matrix effects on 81 oxygen isotopic compositions in carbonates: Journal of Analytical Atomic Spectrometry, doi: $82 \quad 10.1039 / \mathrm{c} 0 \mathrm{ja} 00213 \mathrm{e}$.

83 Rollion-Bard, C., Mangin, D., and Champenois, M., 2007, Development and application of 84 oxygen and carbon isotopic measurements of biogenic carbonates by ion microprobe: 85 Geostandards and Geoanalytical Research, v. 31, p. 39-50. 

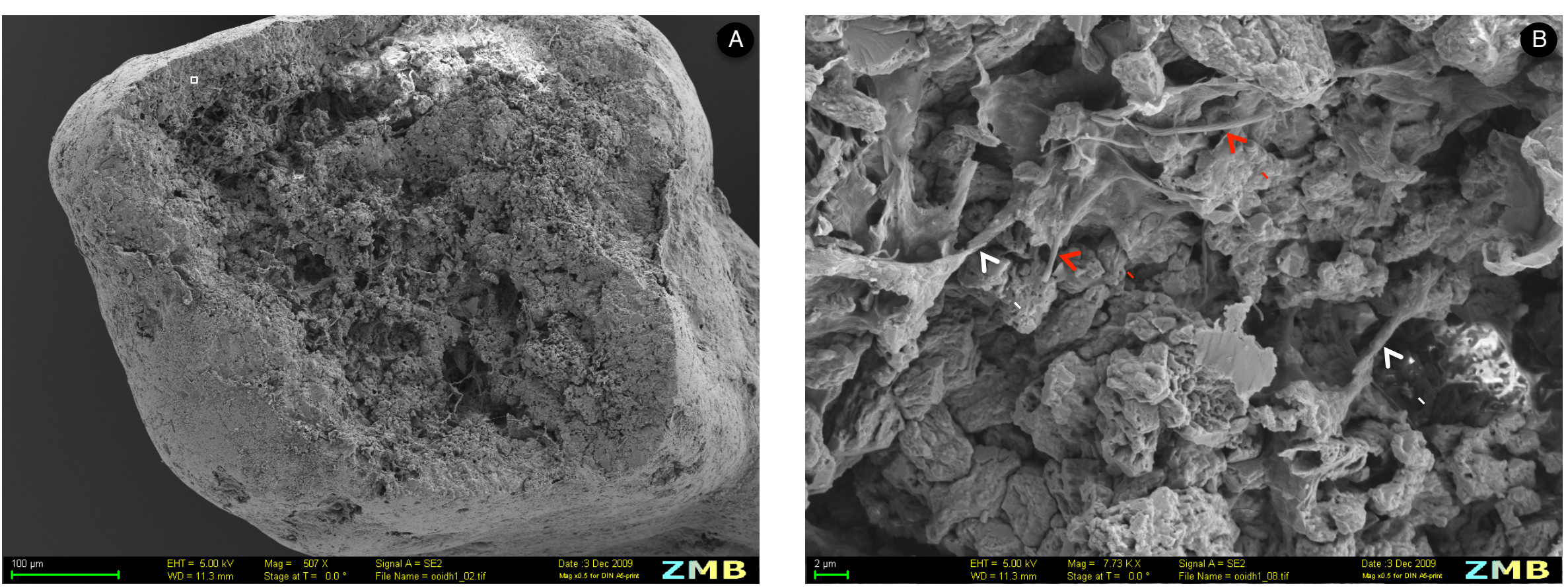
Supplemental figure 2
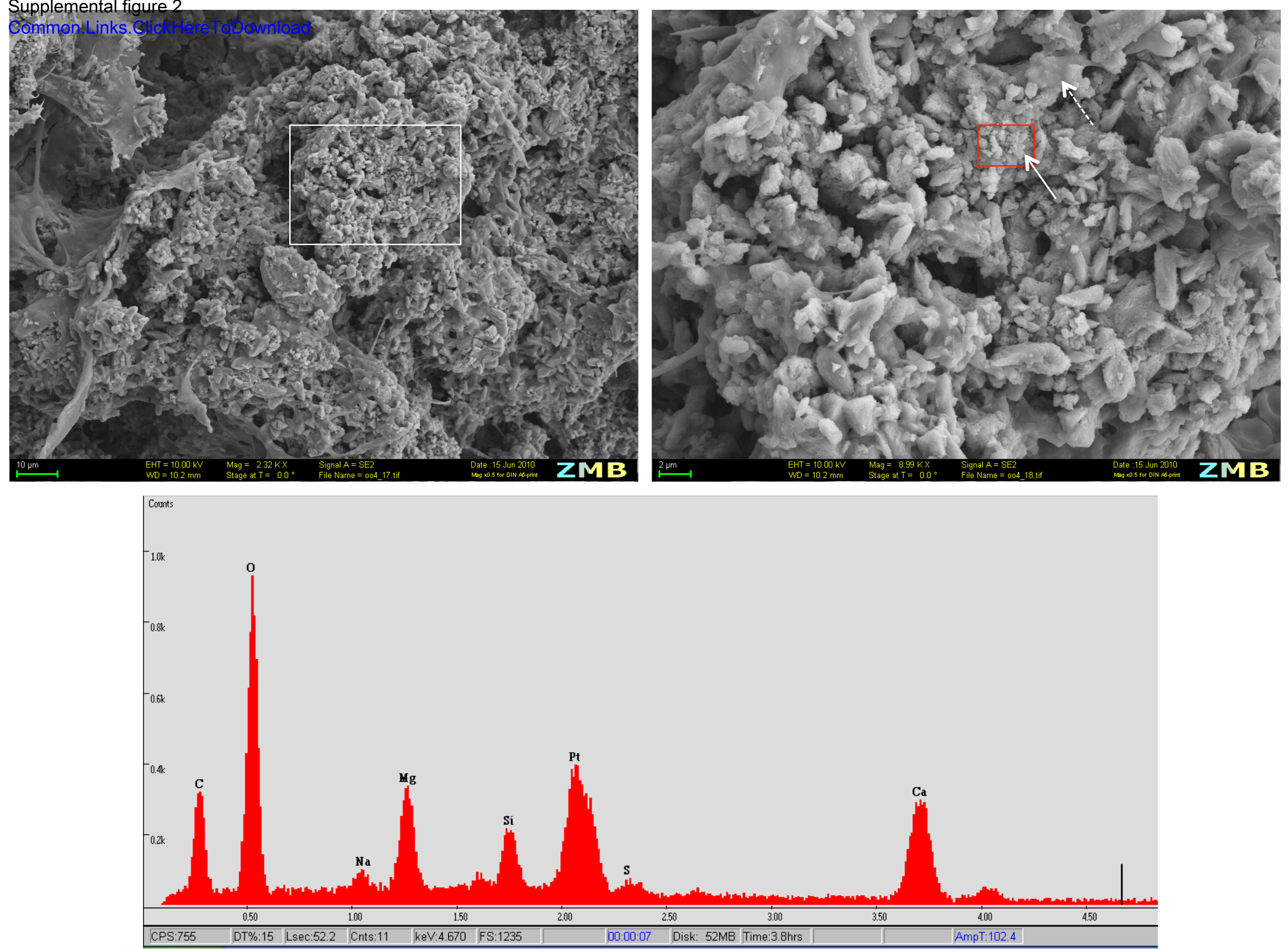


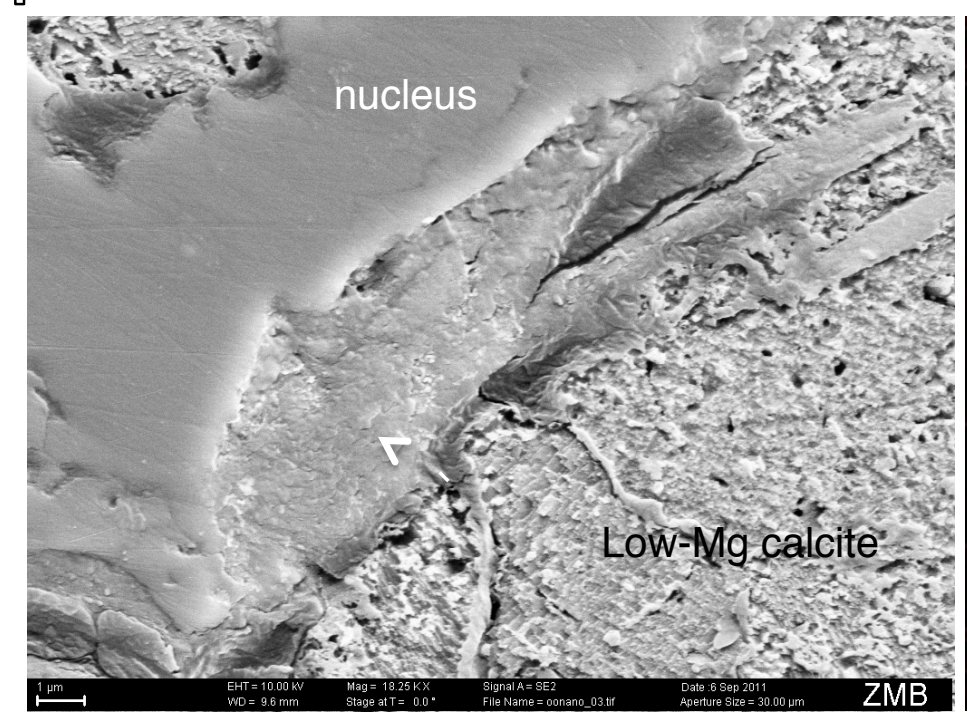

(C)

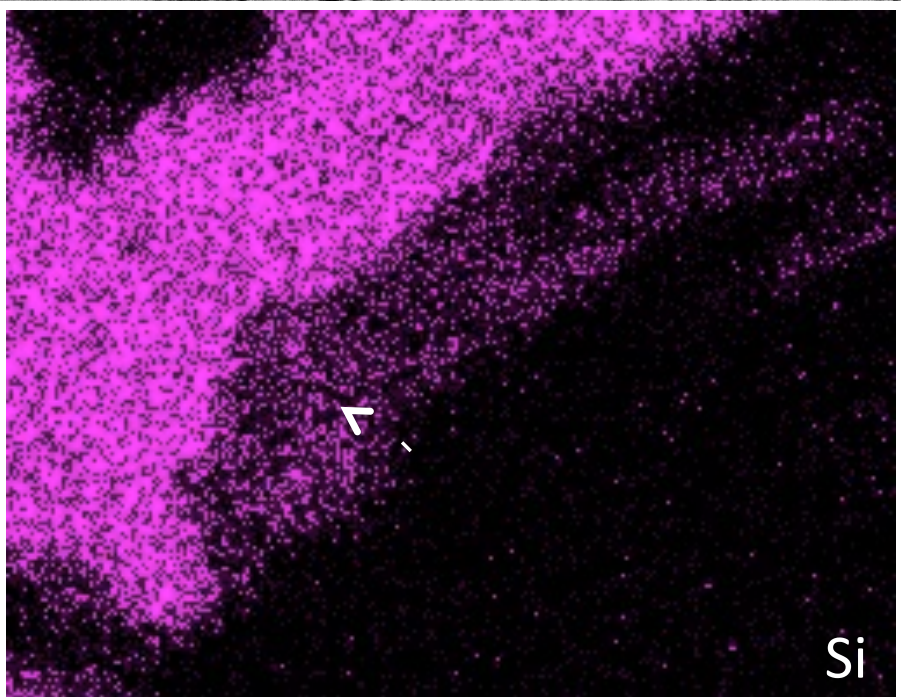

